\title{
Horizontes, trayectosy recorridos de la sociología de la cultura y de la sociología de las religiones en el Perú
}

Sección ESTUDI0S

RECIBIDO: 31/08/2020

APROBADO: 15/09/2020

PUBLICADO ONLINE: 23/10/2020
Imelda Vega-Centeno $B$.

Centro Bartolomé de las Casas, Perú

imelda@qiqmapunku.org

https:/orcid.org/0000-0002-0179-2498

\section{RESUMEN}

Los temas de religión y cultura han sido fundamentales para el conocimiento del Perú, inclusive antes de su existencia como nación en el contexto internacional. No se trata de temas que pusieran de "moda intelectual" algunos marcos teóricos ni determinadas teorías de interpretación de la realidad, los fenómenos socio-culturales y religiosos los precedieron. Es en esta larga duración es que tenemos que inscribir el surgimiento de los estudios sobre la religión y la cultura en las poblaciones andinas. Retomar este largo recorrido nos permitirá situar los esfuerzos analíticos e interpretativos, así como las recolecciones etnológicas que se produjeron desde hace más de quinientos años, y de esta manera enriquecer nuestro conocimiento de los fenómenos estudiados a fin de situarlos dentro del esquema interpretativo que permite ubicar al Perú como nación.

PALABRAS CLAVE: religión; cultura; larga duración; pluridisciplinariedad.

\section{Horizons, paths and routes of the Sociology of Culture and the Sociology of Religions in Peru}

\section{ABSTRACT}

The subjects of religion and culture have been fundamental for the knowledge of Peru, even before its existence as a nation in the international context. These are not issues that put some theoretical frameworks or certain theories of interpretation of reality into "intellectual fashion"; socio-cultural and religious phenomena preceded them. It is in this long duration that we have to register the emergence of studies on religion and culture in the Andean populations. Retaking this long journey will allow us to locate the analytical and interpretive efforts, as well as the ethnological collections that took place for more than five hundred years, and in this way enrich our knowledge of the studied phenomena in order to place them within the interpretive scheme that allows locating to Peru as a nation. KEYWORDS: religión; culture; long duration; pluridisciplinarity. 


\section{Introducción}

os temas de religión y cultura han sido fundamentales para el conocimiento del Perú, inclusive antes de su existencia como nación en el contexto internacional. No se trata de temas que pusieran de "moda intelectual" algunos marcos teóricos ni determinadas teorías de interpretación de la realidad, los fenómenos socio-culturales y religiosos los precedieron. Los grupos humanos que construyeron los pueblos que darían lugar a las naciones andinas -entre ellas el Perú- estaban allí produciendo cultura y practicando ricas religiones originarias, mucho antes del hecho colonial e inclusive desde las formaciones humanas más antiguas y rudimentarias.

Por ello, para el presente trabajo emprenderemos el recorrido que tuvieron que realizar quienes pensaron el Perú, desde sus más elementales formaciones humanas, a las que encontraron produciendo y practicando culturas y religiones sumamente ricas y complejas. Retomar este largo recorrido nos permitirá situar los esfuerzos analíticos e interpretativos, así como las recolecciones etnológicas que se produjeron desde hace más de quinientos años, y de esta manera enriquecer nuestro conocimiento de los fenómenos estudiados a fin de situarlos dentro del esquema interpretativo que permite ubicar al Perú como nación.

\section{Importancia del estudio de la larga duración para el análisis de los fenómenos de religión y cultura}

El estudio de los fenómenos religioso-culturales en las poblaciones andinas fue un tema que llamó la atención de los cronistas y los primeros enviados de la corona española en el lejano siglo XVI. Es cierto que los evangelizadores y funcionarios, que luego serían cronistas, tenían como misión "anunciar el evangelio", pues habían sido asociados a la tarea de la conquista como evangelizadores de los habitantes del nuevo mundo; desde el pensamiento de la Iglesia Romana la conquista era una tarea evangelizadora, y la garantía de que así sea era justamente la presencia de los representantes de las grandes órdenes religiosas, presentes desde el inicio en la tarea colonial.

Estudiar a los habitantes del Nuevo Mundo, sus formas de pensar, de organizarse, acercarse al contenido de sus creencias, ritos y mitos era parte fundamental de la tarea de la conquista, y a ella se dedicaron los cronistas, la mayoría de los cuales fueron miembros de las congregaciones religiosas, aunque no faltaron funcionarios letrados de la corona que emprendieron el mismo trabajo. 
El estudio de la religión y la cultura fue pues una tarea inicial y de gran envergadura que emprendieron los cronistas, era indispensable para conocer al "otro", al que tenían que evangelizar, obviamente, que el objetivo era conocer "sus errores y supersticiones" a fin de convencerlos de que se conviertan al Dios verdadero - el de los conquistadores - y que prohijados bajo la mansedumbre de la relación catecumenal, dócilmente aceptaran el dominio de los conquistadores.

Al emprender esta tarea la mayoría de los cronistas fue autodidacta, el interés era recolectar la tradición oral aun vigente en los pueblos dominados, y al conocerla poder desmontar el soporte de creencias y moral que proveían a los pueblos dominados. Pero esta tarea no era fácil, existía la barrera del idioma, para ello no pocos cronistas se tuvieron que dedicar al estudio de las lenguas aborígenes, para poder acceder a la información que algunos se allanaban a dar, pero había que superar la hostilidad de la desconfianza, el temor, el miedo, producto de los choques de la conquista, y de las certezas que les proveía la cultura originaria a los aborígenes americanos y que los enfrentaba con el estilo y métodos de la nación invasora (Wachtel, 1974).

En esta larga duración es que tenemos que inscribir el surgimiento de los estudios sobre la religión y la cultura en las poblaciones andinas. Ambos forman parte del ethos fundamental de los pueblos, y fueron la piedra de choque que confrontó a la invasión colonial desde sus inicios. Nada más diferente a los sobrios ritos romanos, a una liturgia rígida y un calendario litúrgico hecho de acuerdo a los ciclos estacionales del hemisferio norte - por cierto que desde sus principios la iglesia romana se acomodó a los ciclos solares vigentes en los pueblos europeos-, los mismos que calendáricamente se sitúan exactamente al revés que los ciclos calendáricos del hemisferio sur (Cox, 2002).

Para los cronistas toda esta información era incomprensible, y era leída en términos de herejía y de tentaciones satánicas, por ejemplo el reordenamiento del calendario juliano por el gregoriano, se acercaba al calendario solar inca, pero llegar a comprender que el solsticio de invierno - cristianizado por la Navidad - caía a fines de junio, era prácticamente una herejía. Entender que una ciudad como el Cuzco no era una "polis" en el sentido romano de la ciudad, sino una ciudad-ritual, que existía por un calendario religioso solar que en ella se graficaba y celebraba, es algo que nunca llegaron a comprender, y que muchos religiosos hoy no entienden aun (Cox, 2002).

De esta manera vemos que, la lógica religioso-cultural de los pueblos andinos era muy distinta a la lógica europea que traían los conquistadores, más aún, éstos estaban imbuidos de la "defensa de la religión" producto de la historia de la invasión 
árabe y judía en España, cuando no de los más recientes debates en torno a la Reforma protestante. La lógica europea de los cristianos españoles y de los miembros de las órdenes religiosas no sólo eran defensivas frente a una competencia religiosa muy distinta, sino que iban a la defensiva de los "fueros de la iglesia" que había perdido gran parte de su fuerza hegemónica medieval.

Aunque hubo cronistas excepcionales como el padre Bernabé Cobo, que hizo un trabajo etnográfico excepcional en su recopilación sobre la Historia de los Incas, la capacidad comprehensiva de los fenómenos religioso-culturales recopilados fue limitada y frecuentemente estuvo empapada de los prejuicios culturales, religiosos y biologistas que no se preocupaban en verificar las historias que habían recopilado sino que a priori las calificaban de"mentiras, engaños, maledicencias del demonio, productos de la ignorancia y perversidad de estos pueblos". Así, los templos indígenas eran "mezquitas", los auquénidos "corderos de estas tierras", y los estudios de plantas medicinales "suma ignorancia y malignidad de estas gentes" (Cobo, 1890). Se trataba de subrayar la preeminencia cultural, social y sobre todo religiosa de los españoles, por encima de los pueblos a los que habían sido enviados — por el Papa - a evangelizar... y dominar en asociación con la corona española.

\section{Importancia de la religión en el ethos cultural del pueblo andino, grandes etapas}

En la tarea de búsqueda de conocimiento sobre los pueblos a los que debían evangelizar y dominar, los cronistas descubrieron rápidamente la importancia de la cuestión religiosa en el ethos del pueblo, importancia igual o mayor - aunque por razones diferentes - que lo era para los súbditos de la corona española. La labor excepcional del P. Cobo como cronista, por ejemplo, lo lleva a hacer un detallado recorrido por los rituales, calendarios, organización ceremonial, de las creencias andinas. Aunque en sus pesquisas es evidente que busca descubrir el "cúmulo de errores" que estas creencias y prácticas contenían, también es cierto que sus peculiar calidad de investigador lo llevó a descubrir con gran detalle una abundante información sobre los mismos, algo que hoy llamaríamos una rica recolección etnográfica, desgraciadamente esta riqueza iba a la par de los prejuicios coloniales en defensa de la "única fe verdadera", la de los colonizadores, y los evidentes mecanismos de defensa que la actitud colonial suscitaban en los informantes.

Es por ello destacable cómo en los dos cronistas peruanos más notables, la información sobre cuestiones religiosas se ve distorsionada por su afán acomodaticio frente a la posible benevolencia de los españoles, la que se mezcla con la necesidad 
de reivindicar sus creencias ancestrales, y reconocer la superioridad de las creencias traídas por los españoles. Desde las complicadas disquisiciones de Garcilaso, para anteponer el mito de la pareja civilizadora, como mito fundante de la nación inca - a pesar de la fuerza y vigencia universal del mito de los hermanos no-fraternos: mito de los hermanos Ayar — , pasando por el reconocimiento de un "dios creador", que no figura en la mitología ni en el imaginario andino, sino un "dios ordenador", advocación menos relevante para la mentalidad colonial europea del s. XVI. Es evidente que Garcilaso de la Vega está defendiendo en su discurso el ser heredero de dos coronas, la española que le viene por su padre y la inca que le viene por la nobleza de su madre (Garcilaso, 1976, 2009; Pease, 1973). Por su parte Guaman Poma de Ayala no sólo repite la preeminencia del mito de la pareja civilizadora, sino que al presentar su terrible queja al virrey... "Y no hay remedio...., lo hace siempre reconociendo literalmente la preeminencia del cristianismo sobre la "ignorancia y confusión" de las creencias de su pueblo (Guaman Poma, 1936).

A pesar de este juego de subjetividades subyacente a la recolección etnográfica de los cronistas — religiosos, funcionarios coloniales y hasta militares—, sus recolecciones son imprescindibles para un conocimiento profundo de la religión andina, de las prácticas religiosas que los cronistas llegaron a comprobar directamente y de las formas cómo se impuso sobre las mismas la religión cristiana traída por los colonizadores. Por eso, trabajos temáticos de recolección, como los emprendidos por Marzal o por Urbano, son imprescindibles, para el estudio actual de las religiones populares y los sustratos ancestrales que las sustentan (Marzal, 1992, 1994; Urbano, 1981).

Habiendo sido la evangelización la misión primordial de la conquista, y por ello la importancia de la asociación entre la Iglesia Católica y la corona española, se colige la relevancia de la labor de los Cronistas, en particular la de los cronistas religiosos, y la importancia que adquiere la información por ellos obtenida para emprender las políticas coloniales de dominio, aunque entre tanto se produzcan obras excepcionales como lo que hoy se conoce como "Dioses y hombres de Huarochirí", es decir, la crónica del P. Ávila en su urgente misión de extirpación de idolatrías en el s. XVII (Ávila, 1966).

La yuxtaposición de creencias aborígenes reinterpretadas por los cronistas fue fundamental para la elaboración de los manuales de evangelización y las políticas eclesiásticas vaticanas, documentos notables como los emanados por los Concilios Limenses, están imbuidos de estas actitudes que no sólo saturaron el imaginario político, religioso e intelectual de los s XVI, XVII y XVIII, sino bien avanzado el s. XIX y el s. XX, en las ideas de los criollos que construyeron la naciente república peruana. 
En un trabajo reciente, pudimos comprobar cómo una excelente recolección etnográfica de José María Arguedas en los años 40 del siglo pasado, sobre el mito de Inkarrí, sobrevive en él este imaginario colonial, jen uno de los padres del indigenismo y de los estudios antropológicos! A pesar de su inmensa empatía con las creencias del hombre andino, es orillado hacia una interpretación con resabios coloniales de los relatos obtenidos, no poniendo en valor hallazgos originales como el del dios ordenador, y acomodando la narración recogida —-más allá de su literalidad - a un relato creacionista cristiano (Vega-Centeno, 2011). Esta misma desviación colonial en la interpretación de los datos obtenidos, se encuentra frecuentemente en algunos antropólogos e historiadores, particularmente algunos que marcan su pertenencia confesional (Marzal, 1983; Pease, 1973).

Es preciso tener en cuenta que esta marca colonial sobre la preeminencia cultural, social, religiosa, de lo peninsular por encima del ethos del pueblo andino quedó impresa en el inconsciente colectivo, en la visión que los criollos tuvieron de ellos mismos y de su papel dentro de la reorganización social no sólo en la colonial, sino al final de esta en el proceso emancipador.

\section{De la subordinación de lo religioso-cultural a la neocolonialidad instalada en la república}

Así, la visión colonial sobre el ehtos religioso andino, adquirió una carga excluyente muy fuerte, pues sirvió de base para el sistema de dominio y el establecimiento de la colonialidad del poder y del saber. Toda la organización social estuvo basada en el sistema de subordinación religiosa, donde podríamos graficar la situación con la norma de que allí donde los evangelizadores encontraban un lugar de culto, se debía colocar una cruz, desde ese momento el lugar "dejaba de ser de culto pagano y pasaba a ser un lugar santo, de culto cristiano". Son numerosos los estudios antropológicos que se han hecho sobre lugares donde existen wakas —lugares santos precolombinos - coronados por una cruz. En el Cuzco mismo, el sistema de ceques que organiza la ciudad está enmarcado por diversos monolitos o wakas que los señalan como lugares de culto antiguo y encima de los mismos se ha plantado una cruz (Zuidema, 2010). Inclusive hay grandes templos, como Santo Domingo, situado encima de una waka principal como el gran templo del Qoricancha; La Catedral, situada encima del palacio de Wiracoha; o La Compañía situada encima del Amarucancha; todos en el Cuzco, templos que marcan el esquema de una ciudad ritual excepcional, y que son testigos de esta yuxtaposición física, ritual, y 
celebratoria de la fe del pueblo que la produjo y del pueblo que impuso sobre ellos su dominio hace 500 años.

No entraremos en el debate sobre los orígenes del movimiento independentista y los contenidos ideológicos de la gesta libertadora. Lo cierto es que la elite criolla que entró en contacto y luchó con las tropas libertadoras del norte y del sur, no tenía un proyecto independentista ni libertario propiamente tal, la independencia era parte de un proceso de reemplazo de la hegemonía peninsular en tierras que no sólo quedaban muy lejos del centro colonial, sino del cual se habían ido distanciando y separando por razones históricas propias de las pugnas europeas por la hegemonía y el evidente debilitamiento de la corona española dentro del concierto monárquico y colonial europeo de los s. XVIII y XIX.

Los criollos se diferenciaban más de los peninsulares por el lugar de nacimiento que por un proyecto de nación o una visión de lo nacional dentro de las discusiones políticas de aquellos tiempos. Para la mayoría de criollos que participaron en los movimientos independentistas ellos mismos eran más los "herederos" de la hegemonía anterior, y no proponían un cambio de los contenidos hegemónicos ni de los sistemas de explotación y servidumbre que sostenían a la colonia y al poder colonial en sí mismo.

Igualmente, la organización eclesiástica, si bien se había diferenciado del poder colonial en determinados momentos y frente a las formas de servidumbre y mal trato hacia los indígenas y esclavos, no había cuestionado profundamente estos sistemas y aunque solidaria con los más pobres, no dejó de ser un sostén del régimen colonial.

Por estas razones, la confusión organizativa y social que se produce en el momento de la independencia tiene que ver por un lado con el imaginario colectivo de los criollos que se perciben a sí mismos como "herederos" de un régimen colonial caduco, y la distancia ideológica que los separa de los caudillos y movimientos libertadores provenientes del norte y del sur. La importancia de ideologías como el liberalismo, la masonería y el darwinismo social presentes en los caudillos extranjeros tuvo su impacto en las élites criollas que se sintieron parte de los "seres superiores" — porque españolizados — frente a las poblaciones indígenas y esclavas, por ello los inicios de la república arrastran estos resabios coloniales y dejan dentro de la naciente república una fuerte marca excluyente y con una débil carga identitaria que naciera de las culturas andinas de donde provenían sus ancestros.

Por su parte, la iglesia institucional peruana, fuertemente identificada con la colonia, estaba marcada por la cantidad de obispos españoles que la dirigían; después del hecho independiente ocho de los once obispos peruanos partieron a 
España, y Roma tardó casi 15 años en: por un lado, reconocer a los nuevos estados como estados soberanos y por ello capaces de establecer relaciones diplomáticas con el Vaticano, y por otro, en reconocer el hecho independiente para América en sí mismo, pues si bien, antes dichos estados habían sido reconocidos lo eran por ser súbditos de España, con quien Roma tenía óptimas relaciones. Dejando de serlo, y más aun negando el "derecho" de España a colonizar estas tierras, había que repensar absolutamente toda la relación con las nuevas naciones. Por ello los 15 años de no-reconocimiento vaticano de nuestros países como naciones independientes.

En esta situación de vacío eclesiástico, problemas identitarios de los criollos, pugnas entre los caudillos militares - nacionales y extranjeros - el confuso estado nacional naciente fue generando un ambiente de debate de ideas ultramontanas por un lado, anticlericales, confesionales y de discusión sobre las ideologías políticas que estaban en boga en Europa. Poco o nada se pensó sobre lo nacional, sus peculiaridades, las historias regionales, la producción cultural, y, por supuesto, las ideas y prácticas religiosas de estos pueblos.

\section{El liberalismo de los libertadores, la masonería y el racismo biológico-social}

Sin embargo, coincidieron — desgraciadamente - por un lado las ideas surgidas del biologismo neodarwiniano sobre la preeminencia de las que llamaron "razas superiores" y la visión colonial de la preeminencia de los peninsulares sobre los orígenes, ideas y religiones de los hombres del ande. Ratificándose entonces, bajo el manto "moderno" $y$ "libertario", la neocolonialidad del poder y del saber, estableciéndose un sistema social, cultural y político sumamente excluyente que tendrá su versión más cruel en la organización económica y su "sublimación" por las supuestas "enseñanzas religiosas cristianas", enraizadas en los Andes desde hacía más de 300 años, las mismas que eran un curioso sistema de yuxtaposición y reinterpretación de contenidos cristianos conjuntamente con contenido religiosos andinos.

El discurso "moderno" de Bolívar, por ejemplo, chocó con las estructuras arcaicas de organización social que éste encontró en el Cuzco en 1825, al emprender las "reformas bolivarianas" es particularmente severo con la "reforma de regulares", pues el régimen de conventos, mantenidos por el producto del trabajo de las tierras pertenecientes a las Cofradías de indios, sólo vislumbra un sistema económico de enriquecimiento de las congregaciones, sin entender todo el sistema transaccional que estaba detrás y menos aun conocer el sistema de negociación de los curas protectores de indios frente a la crueldad de las reformas toledanas que despojaron 
de sus tierras a los indios. Si con un pensamiento "moderno" Bolívar malentiende el sistema económico y de devolución de tierras a las cofradías de indios, con sus "reformas bolivarianas", no sólo despoja a los Conventos de las tierras que administraban, sino que priva a los indios del sustento que el trabajo de estas tierras les aportaba. Al encontrarse con propiedades, rurales y urbanas, que ya no tenían administradores (conventos) ni trabajadores (cofradías indígenas), Bolívar creó las Sociedades de Beneficencia, dándoles como capital las tierras y propiedades confiscadas, para que dichas sociedades, a su vez, mantengan colegios, hospitales, orfanatorios, etc... la historia de cómo se administraron estos bienes, frecuentemente rayó en la infamia, y no abonan a lucir la clarividencia política de Bolívar. Los conflictos entre Roma y las órdenes religiosas, para que aquella emprenda su defensa frente al sistema confiscatorio bolivariano no harán sino agravar la mala relación entre la iglesia local y el naciente poder político nacional (García Jordán, 1986).

Pero, en este panorama confuso de la naciente república, la situación de exclusión, sometimiento y marginalidad de los indígenas del ande y de los esclavos se fue agravando, eran poblaciones que nunca fueron asimiladas en plano de igualdad a la nación naciente. Se ha escrito mucho sobre el confuso rol que jugaron los indígenas en las guerras de caudillos y más tarde en la guerra del Pacífico, pero era imposible pretender que éstos tuvieran un sistema de identificación con lo nacional, o con los intereses de los independistas cuando eran propugnados por los mismos señores de la tierra o de la espada que los sometían, brutalizaban o humillaban. Al igual que el discurso "moderno" de Bolívar, el discurso de los neoesclavistas darwinianos se revestía de "modernidad" argumentando datos supuestamente "científicos" para someter, marginar y excluir a los descendientes de esclavos y a los aborígenes andinos de los bienes y beneficios de la nacionalidad. Ejemplo de la normatividad excluyente son las "leyes sociales" de la conscripción vial y el servicio civil obligatorio (Vega-Centeno, 1993).

Los finales del siglo XIX tras la debacle de la derrota de la guerra del Pacífico, polarizaron la situación de los indígenas y el débil sistema identificatorio de éstos con "Io nacional". Más aun, al resultar tanto los nuevos propietarios terratenientes los mismos que las autoridades reemplazantes del sistema colonial, las comunidades indígenas despojadas por la república resultaban enfrentadas con sus nuevos representantes y el sistema de haciendas y de poder que se instauró con la independencia. Las revueltas indígenas, el auge de los reclamos de los yanaconas y arrendatarios de las tierras frente al poder de los hacendados con fuerte referencia centralista, oponen a ambos segmentos poblacionales y hacen prever estallidos sociales posteriores, de los que, evidentemente, son precedentes. 


\section{Los ideólogos, los librepensadores, los intelectuales: Bartolomé Herrera, Javier Prado, González Prada, José Carlos Mariátegui}

Tras la derrota en la guerra del Pacífico se impone una nueva estructuración societal y un nuevo ordenamiento social. La iglesia católica ya está reconocida y tiende a consolidarse localmente con la fuerte influencia vaticana que hace girar su vida en el escenario romano y las pugnas entre los principados europeos de las que hacía parte. Para fortalecer su posición frente a dichos principados Roma centralizó su poder y reforzó el ejercicio vertical de su autoridad, teniendo una presencia preponderante en las iglesias locales. Es el período de romanización de las iglesias locales, en el cual la naciente iglesia nacional encuentra pocos referentes para autonomizarse y surgir con un pensamiento y prácticas pastorales propias. Algunos clérigos sobresalen en este período, como Bartolomé Herrera, que si bien tenía un pensamiento político ultramontano en materias de organización política, por haber sido cura de pueblo tenía una fuerte sensibilidad frente a las demandas de las comunidades indígenas. Por eso desde su podio como diputado abogó por el reconocimiento de los derechos de las comunidades andinas y el reconocimiento de los derechos de los esclavos recientemente libertos. Sin embargo, en estas luchas que eran ideológicas y políticas, el enfrentamiento de la iglesia con el liberalismo de Ramón Castilla, tiene más que ver con el anticlericalismo y ateísmo de sus referencias liberales europeas y menos con sus prácticas sociales de reconocimiento de los derechos de los afrodescendientes y de las comunidades indígenas. Es decir son confrontaciones ideológicas de las respectivas cúpulas de poder, más que cuestionamientos sobre prácticas pastorales.

Es también hacia fines del s. XIX que resurge el interés por lo religioso en las prácticas sociales, sobre todo en las de las Ilamadas masas populares. El resurgimiento de la iglesia institucional trata de aprovechar de la pervivencia de la fe espontánea de estos pueblos, y de la forma cómo había supervivido al tiempo de abandono eclesiástico después de las guerras de la independencia. Javier Prado escribe un notable trabajo sobre la fe popular en el Cristo de los Milagros, y su impronta permanece como un hito en el entendimiento de la cultura y religión populares. José Carlos Mariátegui se inspira en éste autor para su ensayo sobre la Religión en su célebre obra (Mariátegui 1973, Klaiber 1987, García Jordán, 1986). Por su parte Manuel González Prada inspirado en el librepensamiento europeo, cuestiona fuertemente la "asfixiante religiosidad" de la sociedad limeña de la que su familia hacía parte, cuestiona el poder eclesiástico y socaba la defensa de los indígenas hecha por algunos sacerdotes defensores de indios. 
El surgimiento de las primeras ideas sociales, y de la sociología como disciplina académica, a comienzos del s. XX, también está marcado por estas obras, así como por el debate político y académico, que surge sobre todo a partir de la presencia de importantes católicos influyentes en la escena política, como Víctor Andrés Belaunde, o la obra pionera de Roberto Mac Lean y Estenós.

Los más ardorosos debates en esta perspectiva se inscriben en el período de Leguía, a partir de 1919, justo después del primer gran estallido de rebeliones indígenas. Los diputados no pueden quedar ajenos a la convulsión social, y comienzan a vislumbrar un nuevo ordenamiento legal que garantizase no tanto los derechos, como sí el sometimiento de las comunidades andinas. Al mismo tiempo desde el Ejecutivo, Leguía propugna leyes que retóricamente reconocen los derechos indígenas, y encarga liderar su puesta en práctica a un conjunto de notables liderados por los obispos locales. Leyes que si bien podían tener el germen del reconocimiento de los derechos de los indígenas, eran encomendadas a instituciones y personas que no tenían capacidad de llevarlas a la práctica, no sólo porque carecían del poder para hacerlo, sino porque no estaban dotadas de los medios económicos para llevarlas a cabo. Un católico ultramontano que destacó en estos debates fue Víctor Andrés Belaunde, los conductores de los dos más importantes patronatos de la raza indígena fueron Mons. Fidel Olivas Escudero en Ayacucho y Mons. Pedro Pascual Farfán de los Godos en el Cuzco (1924 y ss.) (García Jordán, 1986, Vega-Centeno, 1993).

En este período una obra que marca un hito en la historia de las ideas contemporáneas, así como en los análisis de los fenómenos religioso-culturales producidos en estas tierras, son los Siete ensayos de interpretación de la realidad peruana, de José Carlos Mariátegui (1928). Si bien, este conjunto de trabajos está motivado por la urgente respuesta a la obra de Manuel García Calderón, quien publica en Francia: Le Pérou contemporain, y es una interpretación eurocéntrica y ultramontana de la joven república. Mariátegui, quién conoció la obra durante su exilio europeo, al mismo tiempo que se imbuyó del pensamiento marxista, acomete este trabajo para dar otra lectura a la realidad peruana, y destacar las peculiaridades de la misma como el bagaje histórico cultural con el que emprende su recorrido por la historia del siglo XX. Por ello no es de extrañar que uno de los ensayos mariateguianos esté dedicado a la religión. Los ensayos tienen una pretensión más global, abarcar los temas principales que componen la realidad nacional: la evolución económica, el problema del indio, el problema de la tierra, la instrucción pública, el factor religioso, regionalismo vs. centralismo y un "proceso" o enjuiciamiento de la literatura nacional. 
El ensayo sobre El factor religioso, abarca tres períodos: La religión del Tahuantinsuyo, La Conquista católica y La Iglesia en la independencia. Su recorrido busca superar el anticlericalismo ateo del período anterior y reivindica los aportes culturales del factor religioso precolombino en su complejidad y peculiaridad. Para Mariátegui la religión del Tahuantinsuyo fue teocrática, que resultó sometida a la dominación española, aunque sobrevivieran prácticas mágicas panteístas. El hecho colonial es reinterpretado como una cruzada, empresa militar y religiosa, que posteriormente en la colonia se consolida como una empresa política y eclesiástica. Reconoce el enorme papel cultural realizado por las congregaciones religiosas así como la capacidad de conmover y conquistar al hombre sencillo con sus prácticas rituales y sermones, lo que produce — según Mariátegui- el fenómeno sincrético en las religiones andinas. Una evaluación final lo lleva a afirmar que el rol de la iglesia católica fue sostener el poder colonial, y que las confrontaciones entre la iglesia y la corona fueron eventuales y circunscritas a problemas concretos, pero no cuestionamientos de principios. En la república, "la independencia así como no tocó los privilegios feudales tampoco lo hizo con los eclesiásticos". Relieva el papel de Manuel González Prada, su cuestionamiento radical y su liderazgo anticlerical. Para Mariátegui el marxismo debía propugnar el cambio del régimen que había permitido pervivir las taras coloniales y de esta manera propender a una nueva organización social (íbid.).

Cabe notar, más cerca de nosotros, un esfuerzo reflexivo de "pensar el Perú", fue la obra colectiva publicada por el CEDEP: Perú Identidad nacional (1979). En las diversas aproximaciones disciplinarias que interrogan la realidad nacional para definir nuestro proceso identitario, figuran dos trabajos sobre la relación cultura y religión, uno de un antropólogo y otro de un teólogo con fuerte formación humanista, selección que pone en relieve la importancia de lo religioso y de la producción cultural en el proceso de construcción de lo nacional (Arróspide et al., 1979).

Con la institucionalización de la sociología y la Antropología, después de mediados del siglo XX, progresivamente el interés académico se centró en los estudios sobre la marginalidad, los fenómenos concomitantes con la marginación y la organización gremial. Son años de fuerte influencia economicista en las Ciencias Sociales y de fuerte debate ideológico sobre los cuadros teóricos que las rigen. El interés sociológico por la cultura es reciente, y se refiere sobre todo a lo que vendría a ser una sociología de las culturas populares, los estudios sociológicos sobre religión existen desde hace cierto tiempo, pero en menor proporción que los estudios antropológicos sobre el mismo tema. Como hace algunos años realizamos un trabajo de exploración sobre el proceso de institucionalización y consolidación del campo 
académico de la sociología en el Perú, en los siguientes acápites retomaremos la reflexión entonces realizada, añadiendo y comentando críticamente los recorridos académicos desarrollados desde entonces (Vega-Centeno, 1996, p. 133).

\section{La lenta metamorfosis de los estudios académicos sobre religión y cultura. Marcos conceptuales, experiencias de campo}

\subsection{Sociologia de la cultura}

El antecedente más importante, de lo que hoy quiere ser una sociología de la cultura, es el famoso ensayo sobre las culturas de la dominación de A. Salazar Bondi (1971), trabajo de observación aguda y abundante, sobre aspectos culturales de nuestro ser social, aunque por su naturaleza misma, dicho trabajo tenga ciertas carencias explicativas. Por otro lado, desde la década de los 40, la antropología venía haciendo investigaciones en el área de la cultura, cuyos centros de interés eran fundamentalmente el estudio de la cultura andina y los procesos de cambios que esta sufría con la migración a las ciudades. La primera etapa de los trabajos de Arguedas y del IEP se inscriben en esta línea; así como el ya clásico trabajo de Quijano sobre el proceso de cholificación (1964). Por su parte la psiquiatría y la psicología social también se interesaron por los fenómenos culturales, Mariátegui J., Rotondo, Bambarén y otros, aportaron al análisis con sus observaciones sobre los procesos de adaptación/desadaptación de los migrantes andinos al mundo de la ciudad, desde la década del 60 (Vega-Centeno, 1996, pp. 133-134).

Sin embargo, con la irrupción del marxismo se abandona completamente esta área temática, y se le niega toda capacidad explicativa, se superpone a ella el concepto supuestamente omnisciente de clase social, con las consecuencias del sesgo economicista que atraviesa el análisis sociológico desde ese momento; se abre entonces un largo paréntesis, en cuanto a una aproximación sociológica de la cultura, que sólo se cierra avanzados los años 80 . En estos últimos tiempos, la producción en sociología de la cultura es considerada "menor", no se discute y algunos tienen dificultad en reconocer su autonomía y su capacidad explicativa. Cabe notar que con la crisis del marxismo sumada al no-manejo de las metodologías tradicionales de la sociología, algunos han convertido la cultura y los métodos cualitativos que ésta requiere, en un nuevo cajón de sastre, donde se "arruman" una serie de hechos sociales sin que estos tengan mucho que ver con la producción cultural propiamen-

1 A partir de este acápite retomamos las principales líneas de reflexión del capítulo VI del mencionado trabajo, teniendo como base una versión preliminar a la publicación de 1996. 
te tal. Lo que ha significado un empobrecimiento de la capacidad analítica y de conocimiento de los fenómenos de cultura que se producen aquí y ahora.

La sociología recibe el desafío del psicoanálisis, cuando en los 80 éste se interesa por los aspectos de cultura; proceso en el que intervienen también la historia y la antropología. De esta manera los estudios de cultura no sólo se convierten en lugar de encuentro entre disciplinas afines, sino en un lugar de inteligibilidad de lo social, pues permiten ampliar el análisis hacia la larga duración. En esta perspectiva, la cultura juega un papel liberador de la sociología, la misma que por el economicismo anterior se había circunscrito al corto plazo; reapareciendo la larga duración en el análisis sociológico se abren las posibilidades de los estudios pluridisciplinarios y las temáticas de interés sociológico se amplían casi al infinito. Surgen nuevos temas: lo étnico, el racismo, la génesis de las ideas sociales, estudios de la cultura de las migraciones y de la producción cultural-popular, entre otros sujetos de actualidad (Íbid, p. 134)

\subsubsection{Los grandes temas abiertos}

Un tema fundamental en la sociología de la cultura es el del racismo, el mestizaje, las rupturas étnicas en el país. Desde González Prada existía la interpretación de la causa de la derrota en la guerra con Chile que había sido la falta de integración étnica del país, por eso había que generar nación. Estas ideas son recogidas y trabajadas por la generación del 900, Riva Agüero y Belaunde comienzan a hablar de mestizaje en términos modernos, donde el mestizo es lo criollo, ya que lo andino pareciera que se "disuelve" en la migración, la idea del mestizaje está asimilada a la occidentalización del criollo y opuesta a lo "caduco" del andino, visión que sigue vigente para largos sectores de la población. Estos análisis son cuestionados por la generación de Mariátegui, con quienes la discusión se da en términos de hispanismo e indianismo, aunque este debate no tenga referentes en hechos sociales objetivos, ya que las migraciones andinas aún no eran significativas y la producción de una cultura urbana es incipiente, pero queda en el ambiente como una intuición válida, como horizonte, de que el Perú es un país mestizo con base andina.

Esta visión tiene continuidad en la obra de Arguedas, que en los años 50 la sustenta en Los ríos profundos. Él es testigo de que la música andina no desaparece en la ciudad sino que florece en los coliseos, y que lo andino es la fuente de toda una serie de innovaciones culturales de los migrantes en la ciudad, Arguedas no sólo proclama estas realidades en su obra literaria, sino que las trabaja como antropólogo. El mismo Arguedas en los años 60 reconoce una cultura en tránsito, pero se cuestiona en torno a sus posibilidades de estabilidad, si se trata de una 
cultura cuyo tránsito llegará a marcar o no a la generación siguiente, o si se trata de una cultura con mayor consistencia que puede marcar a otras generaciones y perdurar en medio urbano, esta es la misma pregunta de se plantea Quijano en su trabajo sobre la cholificación (Quijano, 2011, [1964]).

Actualmente los planteamientos interpretativos están abiertos, pareciera que hay una asimilación de lo occidental por parte del hombre andino, inclusive cierto acriollamiento, "se pone mosca", aprende a desconfiar y adquiere mucha libertad respecto a las normas; pero su asimilación a lo urbano no es total, y las pautas andinas se reproducen en la generación siguiente; el florecimiento religioso es uno de los elementos de reproducción cultural, y de innovación en el medio urbano. Por otro lado se está debilitando el criollismo, el vals criollo tiende a ser un género de nostalgia, cosa que no pasa con el huayno ni con la chicha, que son géneros vigentes, lo que demuestra la vigencia de lo andino en la ciudad. En cambio, elementos criollos como "el tarjetazo" desaparecen pues la situación económica le resta cabida; ciertamente el proceso del mestizaje tiende a esclarecerse, con su referente básico andino, mientras que la mentalidad criolla entra en fase de disolución, entre otras características culturales por la debilidad de sus lazos familiares, el machismo, su visión presentista y sensual, muy diferente al ascetismo del serrano que mira al futuro, y para quien el progreso es un desafío personal. Por otro lado, no hay movilidad social por parte del criollo, son sectores que tienden a permanecer en un proceso de desaparición, mientras que la movilidad social de este siglo la protagoniza con particular vitalidad el migrante andino (Altamirano, Matos Mar, Osterling, Golte y otros). ${ }^{2}$

Quizás el área donde se ha abierto más el abanico de posibilidades de análisis de cultura es en el mundo de las migraciones, desde los análisis de Matos Mar y su "desborde popular", hasta las interpretaciones de H. de Soto que intenta una interpretación legalista del fenómeno; por un lado, está C. Franco y su aproximación a la "modernidad popular", que incide en las capacidades de inventiva del migrante; otra perspectiva es la de Flores Galindo y Portocarrero para quienes la migración no es una ruptura radical, encontrando cambios y continuidades; igualmente en los trabajos sobre religión de Marzal se encontrará esta misma perspectiva. Por su parte Degregori con especial sensibilidad por las culturas andinas, y Golte, tratan de interpretar las culturas de migración en sus contextos urbanos y modernos: por ello la línea más trabajada es la de la modernidad, y a partir de ella los migrantes comienzan a ser entendidos y valorados de diferente manera (Vega-Centeno, 1996, pp. 134-136)

2 Para la Bibliografía del presente acápite, ver la Bibliografía de nuestra publicación de 1996, que implica un desarrollo más completo sobre los trabajos en estas áreas. 


\subsubsection{Desafíos planteados}

Actualmente nos encontramos con una situación teórico-metodológica muy abierta, sin pretensiones de un sistema único de explicaciones totales de la realidad, hay pluralidad y libertad de investigación, con una visión más instrumental a partir de conceptos teóricos diferentes, con capacidad de sugerir conceptos, dialogar con los hechos y de producir hipótesis heurísticas; el eclecticismo puede ser enriquecedor, siempre y cuando no se caiga en excesivo relativismo. Convergen además diversas corrientes que permiten entender la cultura desde una perspectiva pluridisciplinaria, el psicoanálisis, la hermenéutica filosófica, Dilthey y Husserl con la idea de horizonte interpretativo, Foucault con sus interpretaciones de las ideas del progreso a comienzos de siglo, y Habermas con su teoría de la acción comunicativa. Aunque estos horizontes teóricos no hayan inspirado en concreto alguna investigación son marcos conceptuales que entran en la discusión actual. Por su parte la sociología francesa con G. Durand y sus conceptos de simbólica e imaginario, Bourdieu sus conceptos de campo, habitus y violencia simbólica, además su crítica de los sistemas educativos y de las funciones del intelectual, son cuestionadores y estimulantes para el trabajo académico; Grignon y Passeron aportan elementos prácticos para el análisis de las culturas populares así como Moscovici es importante para entender la cultura de masas y la importancia de la publicidad en la cultura moderna. Aunque existe un serio problema con las pocas traducciones al español de la mayoría de estos autores, y las dificultades reales (económicas entre otras) de mantenerse actualizado en bibliografía científica internacional (Vega-Centeno, 1996, p. 136).

Una limitación en el estudio de la cultura por parte de la sociología, ha sido el hecho de que en el Perú la antropología y la sociología son dos disciplinas separadas, si la primera tenía como sujeto de estudios la cultura, la segunda lo tenía en las relaciones sociales, como si se tratase de fenómenos separados e inconexos. La tradición anglosajona que se instauró entre nosotros marcó una formación profesional diferente entre ambas disciplinas, orientando a la antropología hacia lo colonial y lo andino y a la sociología hacia el presente y la ciudad; posiciones que no están validadas teóricamente, pero que están presentes en las tradiciones de ambas disciplinas. Objetivamente la antropología ha trabajado más al campesino, inclusive siguiéndolo en su proceso migratorio (Altamirano); en cambio la sociología nació en la ciudad y estuvo más vinculada a la modernidad, aunque sus aportes en el estudio de esta misma tengan que ser cuestionados y deban adecuarse a las exigencias actuales. Por otro lado la sociología ha demostrado más apertura pluridisciplinaria, quizás por la conciencia de sus propias carencias y debilidades, 
del encuentro con historiadores, economistas y psicoanalistas los sociólogos han salido enriquecidos.

Actualmente asistimos a la eclosión de un conjunto de fenómenos culturales nuevos: subculturas, contraculturas, cambios de comportamientos, violencia política y social, todos ellos sujetos de la sociología de la cultura. En este campo un aporte enriquecedor fue el de APEP (Asociación Peruana de Estudios de la Paz), que hizo converger a diversas disciplinas en el estudio de distintos aspectos de la violencia estructural, trabajo a partir del cual se pudo poner en evidencia la violencia de diversas manifestaciones culturales de la vida cotidiana, las que nos hablan de las raíces históricas de la violencia y de las injustas estructuras que la sustentan. Trabajos de este tipo pueden ayudar a entender fenómenos como el terrorismo, pero los mismos forman parte del conocimiento de grupos "ilustrados" y no han llegado al sentido común de la población, vacío que habría que llenar, pues los mismos podrían contribuir a solucionar las fracturas en nuestro país, las que son hondas y sumamente riesgosas.

Al ser la sociología de las culturas una nueva pista de estudios que se abre a la imaginación sociológica, se puede señalar un sin fin de temas por trabajar, entre ellos la necesidad de trabajar los procesos históricos de producción cultural, el proceso de la cultura criolla, los fenómenos de las culturas populares y sus manifestaciones religiosas y políticas, trabajar la tradición oral y el sistema de signos símbolos y explicaciones que nos constituye como peruanos, cómo se está produciendo el mestizaje hoy entre nosotros; trabajar las diversas culturas generacionales, las visiones de grupos que se aferran al presente y niegan el pasado; y por supuesto, el trabajo de la conceptuación adecuada específica en esta área para poder construir marcos teóricos heurísticos, ricos en hipótesis que ayuden cuestionar para comprender y transformar nuestra realidad (Vega-Centeno, 1996, pp. 136-138)

\subsection{Sociología de las religiones}

Los trabajos sobre religiones son antiguos en el Perú, desde los estudios fomentados por los etnólogos de las Universidades San Marcos en Lima, y San Antonio Abad en el Cuzco, que desde los años 40 produjeron trabajos de notable interés. En la Universidad Católica el interés por el estudio de las religiones surgió desde la década del 50, con 0 . Ferrero que introdujo los estudios de M. Eliade sobre historia de las religiones. Tradicionalmente estos estudios, han sido área de interés disciplinario de la antropología, aunque en sus inicios en la Facultad de Ciencias Sociales de la Universidad Católica hubo influencias de la sociología francesa de las religiones: $F$. 
Boulard, E. Pin y F. Houtart. Pero pronto se abandonaron estos temas, puesto que en sociología el sujeto único de estudios vino a ser: las clases sociales.

Después de un período de cierto olvido, las nuevas corrientes dentro de la Iglesia Católica, posteriores al Concilio Vaticano II y a la Asamblea del CELAM en Medellín (1968), renuevan el interés y revalorizan los estudios en Ciencias Sociales sobre las religiones, de modo que un conjunto de instituciones promovidas por la iglesia se convierten en lugares de reflexión y estudios: en el área de la sociología de las religiones: destacan primero el Instituto de Pastoral Andina, 1968; y el CAAAP en 1972; ambos vinculados a iniciativas institucionales de los obispos del sur andino y de la amazonia, los que promueven estudios sobre las religiones andinas y amazónicas, los mismos que se difundirán en las revistas de dichas instituciones, Allpanchis, Shimpihui y Amazonía Peruana.

Surgen otra serie de centros de investigaciones, vinculados a la iglesia católica pero con más interés científico, como el Centro de Estudios Regionales Andinos Bartolomé de Las Casas, del Cusco, el cual ha hecho una notable contribución bibliográfica en temas de historia, evangelización y otros directa o indirectamente vinculados con las religiones andinas, los estudios del período colonial y los archivos eclesiásticos. Igualmente con interés académico y cierto interés pastoral surgirán posteriormente CETA en Iquitos e IDEA en Chucuito, Puno. En el área de difusión de ciertas reflexiones entre científicas y pastorales, debemos anotar a la revista del CEP, Páginas.

Es preciso señalar que tanto la sociología como la antropología son aspectos de un mismo análisis, cuyas metodologías tienen a acercarse cada vez más entre sí. Si la antropología inicialmente se interesaba más en la forma cómo la religión ayudaba a mantener la cultura, la sociología se interesaba en las implicaciones políticas e ideológicas de las religiones y de su función social. Posteriormente la antropología se comienza a interesar por las religiones populares, que se producen en medios urbanos culturalmente heterogéneos, y allí se encuentran con las preocupaciones de una sociología que comienza a rescatar los temas clásicos como las representaciones colectivas y los fenómenos de carisma y religión (Durkheim, Weber).

Frente al hecho social objetivo de la llamada "explosión sectaria" se ha producido un renovado interés por estudiar los fenómenos religiosos en el Perú, fenómeno de visibilidad de diversas confesiones de origen reformado o inclusive no propiamente cristianas, que incursionan en diversas actividades públicas, visibilidad que sobredimensiona su importancia, pues según el Censo de 1993, a nivel nacional el $90 \%$ de la población del país era católica, y para Lima metropolitana sería el 96\%. Posteriormente los censos del 2005 y Censos mandados hacer por las denomina- 
ciones involucradas afirman que la presencia de los Nuevos Movimientos Religiosos es mucho mayor, hasta un 15 y 17\%, disminuyendo notablemente el "monopolio católico" en el sistema de creencias registrado censalmente. La presencia de los Nuevos Movimientos Religiosos y las llamadas "sectas" hacen que los científicos sociales se pregunten el porqué de su surgimiento y desarrollo, cuál es el tipo de destinatario de la actividad proselitista, qué tipo de conversión provocan, y cuál es su influencia en la vida política y social. Esta es una perspectiva de estudios sobre la religión como elemento fundamental de cultura, la misma que es una superación de la simplificación marxista de los 70 para quienes las religiones eran superestructura y nada más.

Sin embargo, existe un problema epistemológico para los estudios sobre religión promovidos por las instituciones eclesiásticas (católicas y otras), y es que no siempre logran el distanciamiento necesario del sujeto de estudios, desvirtuando el análisis con actitudes apologéticas. Para las áreas de la sociología que toman aspectos totalizantes de la vida del individuo, como son la política y la religión, es más necesario que en otras áreas el ateísmo metodológico del que habla Maduro (1979), pues ésta actitud permite hacer de los fenómenos religiosos (y políticos) objeto de Ciencia Social: se trata de cuestionar la evidencia de estos fenómenos, pero sin pretender que los resultados de este procedimiento tengan una validez absoluta. Para trabajar científicamente en ciencias sociales de las religiones, hay que reconstruir los fenómenos religiosos como productos sociales relativamente autónomos, con efectos sociales pertinentes y específicos sobre sus propias condiciones sociales de producción. Esta reconstrucción, para mantenerse crítica, debe reconocerse a sí misma como coyuntural, provisional, parcial y parcializada. Estas son advertencias epistemológicas indispensables para toda producción sociológica, pero cuánto más de aquella que pretende analizar fenómenos de creencia (VegaCenteno, 1996, pp. 138-139).

\subsubsection{Estudios sobre religiones}

Cuando se inicia esta etapa de estudios de la religión, los enfoques evolucionistas habían sido superados en la antropología; las cuestiones sobre cuáles son las funciones que cumple la religión, en la vida de los individuos y colectividades, por ello toman elementos del estructural-funcionalismo para buscar entender dichas funciones sociales. En la década del 60 son clásicos los estudios de religión sobre comunidades, luego se relieva el interés por estudiar las fiestas religiosas y su entorno económico, estudiarlas como parte de un sistema de redistribución de poder y de igualación social. Posteriormente se cambia por un enfoque más simbólico, 
con énfasis en las significaciones más que en la función social, la aproximación a lo religioso como sistema simbólico revalora esta área disciplinaria, como ciencias explicativas de los hechos sociales. Posteriormente llegan otros aportes teóricos, la escuela francesa de antropología, G. Balandier, Cl. Lévi-Strauss, S. Moscovici; y trabajos sociológicos anglosajones como los de P. Berger y T. Luckmann; de la sociología francesa llegan D. Hervieu-Léger, J. Poulat, J. Remy, y F. Houtart, pero sobre todo P. Bourdieu; aportes teóricos que renuevan completamente la aproximación sociológica a lo religioso, aunque varios de estos marcos teórico-interpretativos hayan sido menos difundidos entre nosotros.

Las principales pistas de trabajo en los estudios sobre religiones dentro del IPA (Instituto de Pastoral Andina) parten del supuesto que las antiguas religiones andinas tienen valor en sí, posteriormente se llega a la enunciación de que el sincretismo es la otra cara de la inculturación, subrayando de esta manera que los fenómenos de inculturación los produce el pueblo, no las decisiones institucionales. Justamente esta aproximación permite a las religiones institucionales usar pastoralmente estos contenidos religiosos en apoyo a los campesinos andinos y sus procesos emancipatorios.

En la década del 70 convergen en la facultad de Ciencias Sociales de la Universidad Católica un conjunto de investigadores interesados en el estudio de los fenómenos religiosos: L. Millones, J. Osio. F. Fuenzalida, A. Ortiz y M. Marzal; por su parte en el área de sociología había desarrollado cierto trabajo sobre religiones A. Buehler, interés que posteriormente retoma $C$. Romero. Los estudios sobre las religiones ha sido un tema de interés pluridisciplinario de otras instituciones, $\mathrm{M}$. Rostowrowski trabaja temas de historia y religión, I. Vega-Centeno trabaja la implicación mutua entre política y religión, aspectos que también han sido recogidos por J. Ansión. Otros investigadores de estos temas han desarrollado temáticas específicas, D. Irarrázaval religión y mundo aymara, J. Regan y otros religiones amazónicas; C. Flores religiones andinas; $\mathrm{H}$. Muñoz peregrinaciones. En esta área se han hecho varios estados de la cuestión sobre lo investigado, siendo M.Marzal quien más esfuerzos ha hecho en este sentido, desde el punto de vista bibliográfico, hasta ahora, y a pesar del tiempo transcurrido, la bibliografía preparada por J. L. González y M. T. Van Roenselen sigue siendo un referente (1983) (Vega-Centeno, 1996, pp.140-141).

\subsubsection{Perspectivas abiertas}

Una cierta síntesis de lo avanzado en Ciencias de las Religiones se encuentra en el primer capítulo de La transformación religiosa peruana de M. Marzal, en la dinámica de las transformaciones religiosas menores que él postula. Hoy estaríamos 
ante el fenómeno de producción de nuevas religiones, que no sólo tienen alcance local sino que rebasan nuestras fronteras, como el caso de los Israelitas del Nuevo Pacto Universal o de la Iglesia Alfa y Omega. El conjunto de prácticas religiosas que se produce en nuestro medio es cada vez más variado, desde los evangelistas que insisten en la conversión, pasando por los pentecostales que ponen énfasis en las curaciones, hasta los cultos de origen oriental, para no hablar de la infinidad de expresiones y acepciones populares del catolicismo. Todas estas prácticas religiosas despiertan interés de estudio por ser respuestas simbólicas para satisfacer ciertas necesidades de los individuos y colectividades, estamos en una etapa de desarrollo de la disciplina en que las "verdades" que estas prácticas religiosas postulan interesan menos y más las prácticas sociales y de sentido que estas vehiculan (Marzal, 1983).

En la práctica, la aproximación entre las metodologías de la antropología y la sociología para los estudios sobre religiones, ha sido muy fructífera, los historiadores también se han unido a este diálogo pluridisplinario, al mismo tiempo que los cientistas sociales se han dado cuenta de que no pueden estudiar eficientemente los fenómenos religiosos, si no tienen una aproximación histórica. Los trabajos de I. Vega-Centeno y de J. Ansion demuestran que religión y política son fenómenos concomitantes y que son factores aglutinantes de las culturas populares; trabajos que sirven para ir más allá de los fenómenos específicos estudiados, y que permiten generalizar sobre determinadas tendencias y códigos de lectura religiosa de lo real. Por su parte el trabajo de J. C. Cortázar muestra cómo las religiones populares permean inclusive un medio supuestamente secularizado, como es el mundo universitario; a su vez el estudio del variado mercado de oferta religiosa, así como del público que acude a ella, permite tener una visión mucho más amplia y heterogénea de los fenómenos religiosos producidos aquí y ahora (Vega-Centeno, 1996).

Un área complementaria es el trabajo de historia de las religiones, donde evidentemente sobresalen trabajos de historiadores como J. Klaiber, A. Nieto, entre otros, pero algunos sociólogos de han incursionado en la historia como C. Romero, D. Irarrázaval, M. Marzal e I. Vega-Centeno, la existencia de la Comisión de Estudios de Historia de la Iglesia en Latino América (Cehila) ha propiciado la producción y los encuentros pluridisciplinarios.

En esta área disciplinaria existen diversos temas de interés que deberían ser trabajados, no hay un estudio en profundidad sobre completo la actual oferta variada de sistemas religiosos; por otro lado, un tema que estuvo muy en boga en los 60, el de la secularización en su acepción amplia, es un asunto que está lejos de haber sido estudiado; hay aspectos de desacralización de las religiones, privatización de las prácticas religiosas, nuevas formas de respuestas y prácticas religiosas, 
temas que valdría la pena trabajar en una perspectiva analítica. Otro fenómeno no trabajado es el del agnosticismo, de aquello para quienes lo religioso no existe, $y$ ver su influencia en la construcción de la sociedad; trabajar el conjunto de estos temas contribuiría a entender mejor el mundo en que vivimos (Vega-Centeno, 1996, pp. 141-142).

Los trayectos, recorridos de la sociología y la antropología en las áreas de la cultura y las religiones son pues largos, diversos, algunos sumamente ricos que nos ofrecen abundantes materiales para el análisis y la confrontación tanto dentro de las disciplinas como para el trabajo pluridisciplinario. Tanto religión y cultura, como conceptos de las ciencias sociales, y como fenómenos de estudio de las mismas son áreas temáticas abiertas a amplios análisis, y grandes descubrimientos. Su estudio podrá contribuir a responder a grandes preguntas sobre nuestros problemas identitarios no resueltos y sobre nuestras apuestas por el futuro.

\section{Bibliografía}

ARRospide de LA FLoR, C. (1979). PERÚ: Identidad nacional, Centro de Estudios para el Desarrollo y la Participación, Lima: CEDEP.

AVILA, F. (1966). Dioses y hombres de Huarochirí, J.M. Arguedas y P. Duviols editores, Lima: IEP.

BetANZOS, J. de, 2015 [1551] - Suma y Narración de los Incas. In: Juan de Betanzos y el Tahuantinsuyo. Nueva edición de Suma y Narración de los Incas (F. Hernández Astete \& R. Cerrón-Palomino, eds.): 107-440; Lima: Pontificia Universidad Católica del Perú.

CIEZA DE LEÓN, P. (1995). - Crónica del Perú. Primera parte, 354 pp.; Lima: Pontificia Universidad Católica del Perú, Academia Nacional de Historia.

Сово, В., 1890-1893 [1653] - Historia del Nuevo Mundo (M. Jiménez la Espada, ed.), 4 tomos; Sevilla: Impr. de E. Rasco.

Cox, Victoria. (2002). Guaman Poma de Ayala:entre los conceptos andino y europeo dde4l tiempo, Cuzco: Centro Bartolomé de Las Casas editores.

Duviols, P. (2017). - ¿Por qué y cómo Garcilaso heredó de su padre el título de Inca? Una lectura selectiva y comparativa de los Comentarios reales de los Incas y de algunos documentos garcilasistas. In: Pierre Duviols. Escritos de historia andina, tomo II. Cronistas (C. Itier, ed.): 113-152; Lima: Biblioteca Nacional del Perú, Instituto Francés de Estudios Andinos. representaciones plásticas, 1526-1548. Colonial Latin American Review, 19 (1): 151-205.

GARCIA, P. (1986). “La Iglesia peruana ante la formación del estado moderno: 1821-1862”, En HISTORICA, Revista de humanidades., Vol. X, $n^{\circ} 1$, Lima: PUCP. 
GARCILASO DE LA VEGA, I., 1976 [1609] - Comentarios reales de los Incas. Prólogo, edición y cronología de Aurelio Miró Quesada, 2 tomos; Caracas: Biblioteca Ayacucho.

GARCILASO DE LA VEGA, I., 2009 [1617] - Historia general del Perú, edición facsimilar; Cuzco: Municipalidad Provincial.

Guaman Poma de Ayala, F., 1936 [1615] - Nueva Coronica y buen gobierno (Códex péruvien illustré), xxviii + 1168 pp.; París: Institut d'Ethnologie.

KLAIBER, Jeffrey, s.j., (1987), La Iglesia en el Perú. Su historia social desde la Independencia. Lima: PUCP, Fondo editorial.

LAS CASAS, B. de, 1892 [ca. 1561] - De las antiguas gentes del Perú (M. Jiménez de la Espada, ed.), lix + 290 pp.; Madrid: Tipografía de Manuel G. Hernández.

MARIÁTEGUI, J., [1928], 1973, Siete ensayos de interpretación de la realidad peruana, Lima: Editorial Amauta, 28a Edición.

MARZAL, M., 1983, La Transformación religiosa peruana, Lima: PUCP.

MARZAL, M., 1992 y 1994, La Utopía posible: Indios y jesuitas en la América Colonial (15491767). Tomos I y II. Lima: PUCP, Fondo Editorial.

PACHACUtI YAmQUI SALCAMAYGUA, J. de S. C. (1993) - Relación de antigüedades deste reyno del Piru. In: Joan de Santa Cruz Pachacuti Yamqui Salcamaygua. Relación de antigüedades deste reyno del Piru. Estudio etnohistórico y lingüístico de Pierre Duviols y César Itier: 182-268; Cusco: Instituto Francés de Estudios Andinos, Centro de Estudios Regionales Andinos "Bartolomé de Las Casas".

PeASE G. Y., F. (1973). El Dios Creador Andino, Lima: Mosca Azul editores.

PEASE G. Y., F. (1990). - Los Incas en la colonia. In: El mundo andino en la época del descubrimiento: 191-206; Lima:Comisión Nacional Peruana delV Centenario del Descubrimiento Encuentro de Dos Mundos.

QuIJANo, A. (2014). Cuestiones y horizontes. Antología esencial, De la dependencia histórico-estructural a la colonialidad/descolonialidad del poder. Selección y Prólogo. de Danilo Assís Clímaco. Buenos Aires: CLACSO.

RoWE, J. H., 1985 - La constitución inca del Cuzco. Histórica, IX (1): 35-73.

SAlAZAR, A. (1971). "La cultura de la dominación", En: Perú hoy. México: Siglo XXI, editores. SARMiento de GAmbOA, P. (1943). - Historia de los incas, 185 pp.; Buenos Aires: Emecé Editores. URBANO, H. (1981). Wiracohca y Ayar, héroes y funciones en las sociedades andinas. Cuzco: Centro Bartolomé de Las Casas.

Vega-Centeno, I. (1991). Aprismo Popular: Cultura, religión y Política; Lima: CISEPA-PUCP y Tarea coeditores.

Vega-Centeno, I. (1993). Pedro Pascual Farfán de los Godos. Obispo de Indios (1870-1945), Cuzco: Instituto de Pastoral Andina. 
IMELDA VEGa-Centeno B.

Vega-Centeno, I. (1996). La Construcción social de la Sociología. Invitación a la crítica. Lima: Fundación F. Ebert editores.

VEGA-CENTENO, I. (2011)."Inkarrí: etnología, religión y apuesta utópica arguediana”, En: Revista Andina, $n^{\circ}$ 51, Cuzco: Centro Bartolomé de Las Casas.

WACHTEL, N., 1974, Los vencidos. Los indios del Perú ante la conquista española. Madrid: Alianza Editorial.

ZUIDEMA, T. (2010). El Calendario inca: tiempo y espacio en la organización ritual del Cuzco. La idea del pasado. Lima: Fondo editorial del Congreso del Perú, Fondo editorial de la PUCP. 